\title{
Protective effect of the G-765C COX-2 polymorphism on subclinical atherosclerosis and inflammatory markers in asymptomatic subjects with cardiovascular risk factors
}

\author{
J. Orbe ${ }^{\text {a,* }}$, O. Beloqui ${ }^{\text {b }}$, J.A. Rodriguez ${ }^{\text {a }}$, M.S. Belzunce ${ }^{\text {a }}$, C. Roncal ${ }^{\text {a }}$, J.A. Páramo ${ }^{\text {a }}$ \\ ${ }^{a}$ Atherosclerosis Research Laboratory, Division of Cardiovascular Science, Center for Applied Medical Research, Pamplona, Spain \\ ${ }^{\mathrm{b}}$ Department of Internal Medicine, University Clinic, School of Medicine, University of Navarra, Pamplona, Spain
}

Received 16 December 2005; accepted 20 December 2005

Available online 3 February 2006

\begin{abstract}
Background: Cyclooxygenase (COX)-2, a key regulatory enzyme in prostanoid synthesis, plays an important role in inflammatory processes. The $-765 \mathrm{G}>\mathrm{C}$ COX-2 polymorphism has been associated with lower promoter activity in vitro and reduced levels of C-reactive protein (CRP) in atherosclerotic carriers of the $\mathrm{C}$ allele. However, its pathophysiological relevance in vivo has not been fully elucidated.

Methods and results: We assessed the $-765 \mathrm{G}>\mathrm{C}$ polymorphism and COX-2 expression in 220 asymptomatic subjects free of cardiovascular disease, in relation to global vascular risk, carotid intima-media thickness (IMT), and inflammatory markers (fibrinogen, Creactive protein $[\mathrm{CRP}]$, von Willebrand factor $[\mathrm{vWF}]$ and interleukin-6 [IL-6]). Genotype frequencies were: CC (7.7\%), CG (34.5\%), GG $(57.7 \%)$. Among hypercholesterolemic subjects $(n=140), \mathrm{C}$ allele carriers had lower COX-2 expression $(p<0.05)$, reduced carotid IMT $(p<0.01)$ and diminished levels of inflammatory markers CRP, vWF and IL-6 $(p<0.05)$, as compared to GG homozygous subjects. The association between carotid IMT and COX-2 polymorphism remained significant after adjusting for cardiovascular risk factors and inflammatory markers $(p=0.008)$.

Conclusions: In asymptomatic hypercholesterolemic subjects the $\mathrm{C}$ allele of $-765 \mathrm{G}>\mathrm{C} \mathrm{COX}-2$ polymorphism was associated with lower COX-2 expression, and reduced subclinical atherosclerosis and systemic inflammation compared with GG homozygous, thus conferring atherosclerosis protection in this cardiovascular risk population.

(C) 2005 Elsevier B.V. All rights reserved.
\end{abstract}

Keywords: Atherosclerosis; COX-2 polymorphism; Hypercholesterolemia; Inflammation

\section{Introduction}

COX-1 and COX-2 catalyze the rate-limiting step in prostanoid synthesis, converting arachidonic acid into $\mathrm{PGH}_{2}$, the precursor of a family of bioactive prostanoids, including thromboxane $\left(\mathrm{TXA}_{2}\right)$ and prostaglandins (PGs) $[1,2]$. COX -1 is a widely expressed constitutive enzyme that participates in tissue homeostasis. By contrast, COX-2, the inducible isoform, is expressed at low levels in most tissues

\footnotetext{
* Corresponding author. Atherosclerosis Research Laboratory, Avda Pio XII 55, CIMA Bldng., 31008 Pamplona, Spain. Tel.: +34 948 194700; fax: +34948 194716 .

E-mail address: josuneor@unav.es (J. Orbe).
}

but can be stimulated by LPS, growth factors and cytokines, such as TNF- $\alpha$ and interleukin-6 (IL-6) [3,4], being implicated in inflammatory processes, including atherosclerosis, rheumatoid diseases and carcinogenesis [5-7]. A direct role for COX-2 in atherosclerosis can be inferred from studies showing significant expression in human atherosclerotic lesions [8-10], as well as COX-2-derived $\mathrm{PGE}_{2}$ increase in subclinical atherosclerosis $[11,12]$. Paradoxically, recent evidence points to a protective function of this enzyme in cardiomyocytes subjected to oxidative stress [13] and also in late preconditioning after ischemia/reperfusion injury [14]. Thus, it is likely that COX-2 exerts beneficial or detrimental effects depending on the rate of induction, the pathophysiological setting and the ability of specific cells to 
metabolize $\mathrm{PGH}_{2}$ into cytoprotective or proinflammatory prostanoids [15].

Genetic polymorphisms in COX-2 might have an impact on COX-2 expression and prostanoid biosynthesis. Although several naturally occurring polymorphisms have been found in the COX-2 gene, their functional relevance and pathophysiological role remain to be elucidated $[16,17]$. Recently, Papafili et al. have described a common variant in the $5^{\prime}$-flanking region of the COX-2 gene $-765 \mathrm{G}>\mathrm{C}$ that is associated with lower promoter activity in vitro in the presence of the $\mathrm{C}$ allele, and reduced levels of $\mathrm{C}$-reactive protein (CRP), a systemic marker of inflammation, in patients with clinical and subclinical atherosclerosis. This single nucleotide polymorphism (SNP) has also been associated with a reduction in the risk of future clinical cardiovascular events $[17,18]$.

We therefore assessed COX-2 expression, subclinical atherosclerosis and inflammatory profile, in relation to this polymorphism, in subjects with cardiovascular risk factors but free of clinically overt atherosclerotic disease.

\section{Methods}

\subsection{Subjects}

A total of 220 apparently healthy subjects $(80 \%$ males, median age 58 years), referred to the Internal Medicine Department of a single institution (University Clinic of Navarra) for global vascular risk assessment, were studied. Subjects were free from clinically apparent atherosclerotic disease based on (1) absence of history of coronary disease, stroke or peripheral arterial disease, and (2) normal ECG and chest-X-ray. Baseline clinical characteristics, cardiovascular risk factors and metabolic parameters in this population are summarized in Table 1. Exclusion criteria were the

Table 1

Biochemical parameters and cardiovascular risk factors in subjects classified according to the $-765 \mathrm{G}>\mathrm{C}$ polymorphism in the promoter of COX-2 gene

\begin{tabular}{lccc}
\hline & CC $(n=17)$ & CG $(n=76)$ & GG $(n=127)$ \\
\hline Age (years) & $57.1 \pm 9.8$ & $56.5 \pm 10.1$ & $59.4 \pm 10.7$ \\
Sex (male, \%) & 76.4 & 80.2 & 75.8 \\
Glucose (mg/dL) & $105.2 \pm 42.3$ & $106.9 \pm 35.5$ & $103.4 \pm 29.3$ \\
Total cholesterol (mg/dL) & $218.5 \pm 48.1$ & $229.4 \pm 35.4^{*}$ & $214.9 \pm 42.0$ \\
LDL-cholesterol (mg/dL) & $147.3 \pm 38.8$ & $157.1 \pm 31.7^{* *}$ & $142.3 \pm 38.5$ \\
HDL-cholesterol (mg/dL) & $49.1 \pm 14.2$ & $49.9 \pm 13.1$ & $48.4 \pm 13.1$ \\
Triglycerides (mg/dL) & $111.0 \pm 45.1$ & $116.4 \pm 65.1$ & $121.0 \pm 71.5$ \\
Current smokers (\%) & 11.8 & 34.3 & 34.4 \\
Hypertension (\%) & 41.2 & 55.2 & 51.9 \\
Dyslipidemia (\%) & 81.2 & 81.5 & 78.1 \\
Obesity (\%) & 18.7 & 35.5 & 33.1 \\
Diabetes mellitus (\%) $^{\text {COX-2 expression }}{ }^{\mathrm{a}}$ & 17.6 & 9.2 & 11.7 \\
\hline
\end{tabular}

$* p<0.05, * * p<0.01$ vs. GG.

${ }^{a}$ Normalized mRNA $=$ target gene mRNA copies/ $\beta$-actin mRNA copies. presence of severely impaired renal function, arteritis, connective tissue diseases, alcohol abuse or use of nonsteroidal anti-inflammatory drugs in the 2 weeks before entering the study. Other conventional atherosclerotic risk factors recorded were: hypertension (systolic/diastolic blood pressure $>139 / 89 \mathrm{~mm} \mathrm{Hg}$ and/or use of antihypertensive drugs), obesity (body mass index $\geq 30 \mathrm{~kg} / \mathrm{m}^{2}$ ), smoking ( $\geq 1$ cigarette a day), diabetes (fasting glucose $\geq 126 \mathrm{mg}$ / $\mathrm{dL}$ and/or use of pharmacologic treatment), and family history of premature CHD (acute myocardial infarction before 60 years in a first degree relative). A subset of 140 hypercholesterolemic subjects was selected from the total population, on the basis of the following criteria: total cholesterol $\geq 220 \mathrm{mg} / \mathrm{dL}$, LDL-cholesterol $\geq 130 \mathrm{mg} / \mathrm{dL}$ and/or statin treatment. Written informed consent was obtained before participation in the study, and the local committee on human research approved the protocol, which was performed in accordance with the principles of the Helsinki Declaration.

\subsection{COX-2 genotyping procedure}

Peripheral blood mononuclear cells were freshly obtained by centrifugation in a Ficoll gradient (Lymphoprep ${ }^{\mathrm{TM}}$ ). Total DNA and RNA were extracted from these cells using Tripure Isolation Reagent (Roche). To genotype the $-765 \mathrm{G}>\mathrm{C}$ variant, a fragment of $306 \mathrm{bp}$ was amplified by PCR in the presence of $60 \mathrm{nM}$ of the forward primer CF8 (5'-CCGCTTCCTTTGTCCATCAG- $\left.3^{\prime}\right)$ and the reverse primer CR7 (5'-GGCTGTATATCTGCTCTATATGC-3') as previously described [17]. Amplified product was digested with AciI (New England Biolabs) restriction endonuclease at $37^{\circ} \mathrm{C}$ overnight and the resulting fragments were separated by electrophoresis in a $2 \%$ agarose gel, and visualized after ethidium bromide staining. Positive and negative digestion controls were included in all gels.

\subsection{Quantitative real-time RT-PCR for COX-2 expression in peripheral blood mononuclear cells}

Total RNA from mononuclear cells was reverse transcribed, and COX-2 expression was quantified by real-time quantitative PCR as previously described [12]. All samples were assayed in triplicate and values normalized on the basis of their $\beta$-actin content. Melt curve analysis was performed to ensure that only the specific product was amplified.

\subsection{Carotid ultrasonography}

All subjects underwent ultrasonography of the common carotid arteries (CCAs). Ultrasonography was performed with a 5-12 MHz linear-array transducer (ATL $500 \mathrm{HDI}$ ). The measurement of IMT was made $1 \mathrm{~cm}$ proximal to the carotid bulb of each CCA at plaque-free sites. From each individual, the IMT was determined as the average of near- 
and far-wall measurements of each CCA. Carotid artery IMT has been shown to be reproducible $[12,19]$.

\subsection{Systemic inflammatory markers}

Plasma and serum samples were obtained from venous blood between 9 and 10 a.m. after overnight fast, and stored at $-80{ }^{\circ} \mathrm{C}$ until analysis. CRP and IL-6 concentrations were analyzed by a high-sensitive immunoassays system (Immulyte hs-CRP, Diagnostic Product Corporation and Quantikine-HS IL-6, R\&D systems respectively). Plasma fibrinogen activity was measured by a clotting assay (Clauss). von Willebrand factor (vWF) antigen was quantified by an enzyme-linked immunosorbent assay (Liatest vWF, Diagnostica Stago, France). vWF values were expressed as percentage in relation to a calibrated standard curve.

Inter and intra-assay coefficients of variation for all these assays were lower than $8 \%$.

\subsection{Biochemical parameters}

Serum cholesterol, HDL and LDL-cholesterol, glucose and triglycerides were determined on fasting blood samples by standard enzymatic techniques.

\subsection{Statistical analysis}

Mean \pm SD (SE for logarithmically transformed variables) is given for all continuous variables, and absolute numbers and percentages for categorical variables. Differences among genotypes were assessed by ANOVA followed by Bonferroni post-hoc test. When no differences between CG and $\mathrm{CC}$ genotypes were found, they were pooled into the same group, and mean comparisons between genotypes were made by the Student's $t$ test. Deviations of the HardyWeinberg equilibrium were assessed by a $\chi^{2}$ test. Pearson test was performed for correlations of continuous variables. Univariate and multivariate lineal regression analysis were performed to assess the relationship between genotypes, inflammatory markers and subclinical atherosclerosis after adjustment for cardiovascular risk factors and other potential confounders. A two-tailed $p<0.05$ was considered statistically significant.

The statistical analysis was performed with SPSS for Windows software package version 11.0.

\section{Results}

To examine the association of the $-765 \mathrm{G}>\mathrm{C}$ polymorphism with COX-2 expression, 220 asymptomatic subjects with cardiovascular risk factors (mean age $58.1 \pm 10.3$ years, $77.7 \%$ men) were genotyped for this polymorphism by PCR analysis. Subjects carrying CC, CG and GG genotypes were $17(7.7 \%), 76(34.5 \%)$ and $127(57.7 \%)$ respectively, and allele frequencies 0.25 and 0.75 for $\mathrm{C}$ and $\mathrm{G}$ alleles respectively, consistent with the Hardy-Weinberg equilibrium. The 3 groups were comparable in relation to all clinical and biochemical parameters analyzed (Table 1), except for the levels of total and LDL-cholesterol, which were significantly augmented in CG $(229.4 \pm 43.1 \mathrm{mg} / \mathrm{dL})$, as compared to either $\mathrm{CC}(218.5 \pm 48.1 \mathrm{mg} / \mathrm{dL})$ and $\mathrm{GG}$ $(214.9 \pm 42.0 \mathrm{mg} / \mathrm{dL})$ genotypes. Since the expression of COX-2 is regulated by LDL-cholesterol at transcriptional level $[20,21]$, and $C$ allele was previously associated with less COX-2 expression [17], a homogeneous subgroup of subjects with similar cholesterol levels $(n=140)$ was further selected to assess the net effect of this SNP.

\section{1. $-765 G>C C O X-2$ polymorphism in the hypercholes- terolemic population}

The clinical characteristics and cardiovascular risk factors of the 140 asymptomatic hypercholesterolemic subjects (mean age $59.7 \pm 9.4$ years, $77.7 \%$ men) are shown in Table 2. Mean total cholesterol levels were $232.5 \pm 38.7 \mathrm{mg} / \mathrm{dL}$ and LDL levels $158.0 \pm 35.8 \mathrm{mg} / \mathrm{dL}$. $28 \%$ out of the total population were receiving statins and $40 \%$ of hypertensives were taking antihypertensive drugs.

The genotype distribution was as follows: $\mathrm{CC}=12$ (8.6\%), $\mathrm{CG}=46(32.8 \%)$, and $\mathrm{GG}=82(58.6 \%)$; allele frequencies were 0.25 and 0.75 for $\mathrm{C}$ and $\mathrm{G}$ alleles respectively, consistent with the Hardy-Weinberg equilibrium. Clinical and biochemical parameters analyzed in relation to the COX-2 genotypes are also shown in Table 2. Demographic characteristics were similar in the three groups, and there were also no significant differences among genotypes in relation to analytical determinations and anti-atherosclerotic therapy.

\subsection{COX-2 expression in monocytes in relation to the $-765 G>C$ polymorphism}

Results of COX-2 gene expression in blood peripheral mononuclear cells in relation to $-765 \mathrm{G}>\mathrm{C}$ polymorphism are shown in Table 3. The lowest baseline COX-2 expression was found in hypercholesterolemic subjects with CC genotype $(0.10 \pm 0.04)$ compared with the GC $(0.13 \pm 0.02)$ and GG $(0.14 \pm 0.01)$ genotypes. When assembling carriers of the $-765 \mathrm{C}$ allele, mean COX-2 expression was significantly lower $(0.11 \pm 0.06)$ than in GG homozygous subjects $(p=0.04)$.

\subsection{Carotid IMT in relation to the $-765 G>C$ polymorphism}

In order to investigate the association of the COX-2 polymorphism with atherosclerotic plaque development, the carotid IMT was measured as a function of the $-765 \mathrm{GC}$ genotype. As shown in Fig. 1, subjects homozygous for the $\mathrm{C}$ allele had significantly reduced carotid IMT $(0.60 \pm 0.08$ 
Table 2

Biochemical parameters and cardiovascular risk factors in asymptomatic hypercholesterolemic subjects classified according to the $-765 \mathrm{G}>\mathrm{C}$ COX-2 polymorphism

\begin{tabular}{|c|c|c|c|c|}
\hline & Total $(n=140)$ & $\mathrm{CC}(n=12)$ & $\mathrm{CG}(n=46)$ & GG $(n=82)$ \\
\hline Age (years) & $59.7 \pm 9.4$ & $60.1 \pm 8.1$ & $58.2 \pm 9.3$ & $60.6 \pm 9.5$ \\
\hline Sex (male, \%) & 77.7 & 83.3 & 76.1 & 76.5 \\
\hline Current smokers (\%) & 29.7 & 16.7 & 28.3 & 32.5 \\
\hline Hypertension (\%) & 52.9 & 41.7 & 56.5 & 52.5 \\
\hline Obesity (\%) & 35.8 & 27.3 & 41.3 & 33.8 \\
\hline Diabetes mellitus (\%) & 11.5 & 8.3 & 8.7 & 13.6 \\
\hline SBP (mm Hg) & $133.2 \pm 21.7$ & $128.4 \pm 18.6$ & $134.3 \pm 25.1$ & $133.3 \pm 20.2$ \\
\hline DBP (mm Hg) & $83.4 \pm 9.6$ & $81.8 \pm 7.4$ & $83.7 \pm 11.0$ & $83.5 \pm 9.1$ \\
\hline Total cholesterol (mg/dL) & $232.5 \pm 38.7$ & $232.7 \pm 46.3$ & $237.6 \pm 32.9$ & $229.5 \pm 40.7$ \\
\hline LDL-cholesterol (mg/dL) & $158.0 \pm 35.8$ & $159.2 \pm 36.2$ & $164.3 \pm 30.5$ & $154.3 \pm 38.4$ \\
\hline HDL-cholesterol (mg/dL) & $49.6 \pm 13.5$ & $48.3 \pm 14.6$ & $49.7 \pm 13.9$ & $49.7 \pm 13.2$ \\
\hline Triglycerides (mg/dL) & $126.1 \pm 67.2$ & $126.1 \pm 41.2$ & $125.7 \pm 64.4$ & $126.3 \pm 72.3$ \\
\hline Glucose (mg/dL) & $103 \pm 29.3$ & $109.0 \pm 49.8$ & $105.9 \pm 35.7$ & $101.9 \pm 20.3$ \\
\hline Statin treatment $(\mathrm{N} / \mathrm{Y})$ & $101 / 39$ & $10 / 2$ & $33 / 13$ & $58 / 24$ \\
\hline Antihypertensives (N/Y) & $110 / 30$ & $9 / 3$ & $30 / 16$ & $71 / 11$ \\
\hline
\end{tabular}

$\mathrm{SBP}=$ systolic blood pressure, $\mathrm{DBP}=$ diastolic blood pressure.

$\mathrm{mm})$ compared with either $\mathrm{GC}(0.67 \pm 0.14 \mathrm{~mm}, p<0.05)$ and $\mathrm{GG}(0.73 \pm 0.16 \mathrm{~mm}, p<0.01)$ genotypes.

\subsection{Systemic markers of inflammation in relation to the $-765 G>C$ polymorphism}

To further assess whether the $-765 \mathrm{G}>\mathrm{C}$ COX-2 promoter variant would influence the systemic levels of inflammatory and endothelial activation markers, CRP, IL6 , fibrinogen and $\mathrm{vWF}$ concentrations were compared in relation to the different genotypes. As shown in Table 3, subjects homozygous for the $\mathrm{C}$ allele exhibited significantly lower concentrations of CRP $(0.23 \pm 0.03 \mathrm{mg} / \mathrm{dL}$ vs. $0.37 \pm 0.03 \mathrm{mg} / \mathrm{dL}, p<0.01)$ and $\mathrm{vWF}(79.0 \pm 23.2 \%$ vs. $108.5 \pm 45.6 \%, p<0.01$ ), whereas differences in fibrinogen levels did not reach statistical significance. Likewise, carriers of the $\mathrm{C}$ allele also showed significantly lower IL6 levels as compared to GG homozygous $(1.6 \pm 0.4 \mathrm{pg} / \mathrm{mL}$ vs. $2.1 \pm 1.6 \mathrm{pg} / \mathrm{mL}, p<0.05)$.

Table 3

COX-2 expression and inflammatory profile in relation to the COX-2 $-765 \mathrm{G}>\mathrm{C}$ polymorphism in hypercholesterolemic subjects

$\begin{array}{llll}\mathrm{CC} & \frac{\mathrm{CG}}{(n=12)} & \frac{\mathrm{GG}}{(n=82)} & \frac{\mathrm{P}}{\mathrm{C} \text { allele }} \\ \text { vs. GG }\end{array}$

\begin{tabular}{lcccl}
\hline COX-2 expression & & & & \\
Baseline mRNA $^{\mathrm{a}}$ & $0.10 \pm 0.04$ & $0.13 \pm 0.02$ & $0.14 \pm 0.01$ & 0.040 \\
& & & & \\
Inflammatory markers & & & & \\
CRP (mg/dL) & $0.23 \pm 0.03 \dagger \dagger$ & $0.29 \pm 0.02$ & $0.37 \pm 0.03$ & 0.022 \\
IL-6 (pg/mL) & $1.7 \pm 0.7$ & $1.5 \pm 0.8 \dagger \dagger$ & $2.1 \pm 1.6$ & 0.022 \\
Fibrinogen (mg/dL) & $291.7 \pm 85.3$ & $299.4 \pm 63.6$ & $304.7 \pm 87.4$ & $\mathrm{~ns}$ \\
VWF $(\%)$ & $79.0 \pm 23.2 \dagger \dagger$ & $118.9 \pm 42.4 \dagger$ & $108.9 \pm 45.6$ & $\mathrm{~ns}$ \\
\hline
\end{tabular}

$\$ p<0.01$ vs. CC.

${ }^{a}$ Normalized mRNA $=$ target gene mRNA copies/ $\beta$-actin mRNA copies.

${ }^{\mathrm{b}}$ Logarithmically transformed (mean $\pm \mathrm{SE}$ ).

\subsection{Multiple regression analysis}

Taking into account the possible associations between $-765 \mathrm{G}>\mathrm{C}$ and carotid IMT with cardiovascular risk factors and inflammatory markers, further multiple regression analysis was performed to assess whether the reduction in carotid IMT observed in $\mathrm{C}$ allele carriers was independent of potential confounders. As shown in Table 4, the association between both parameters remained statistically significant after adjusting for traditional cardiovascular risk factors and inflammatory markers $(p=0.008)$, with a reduction in

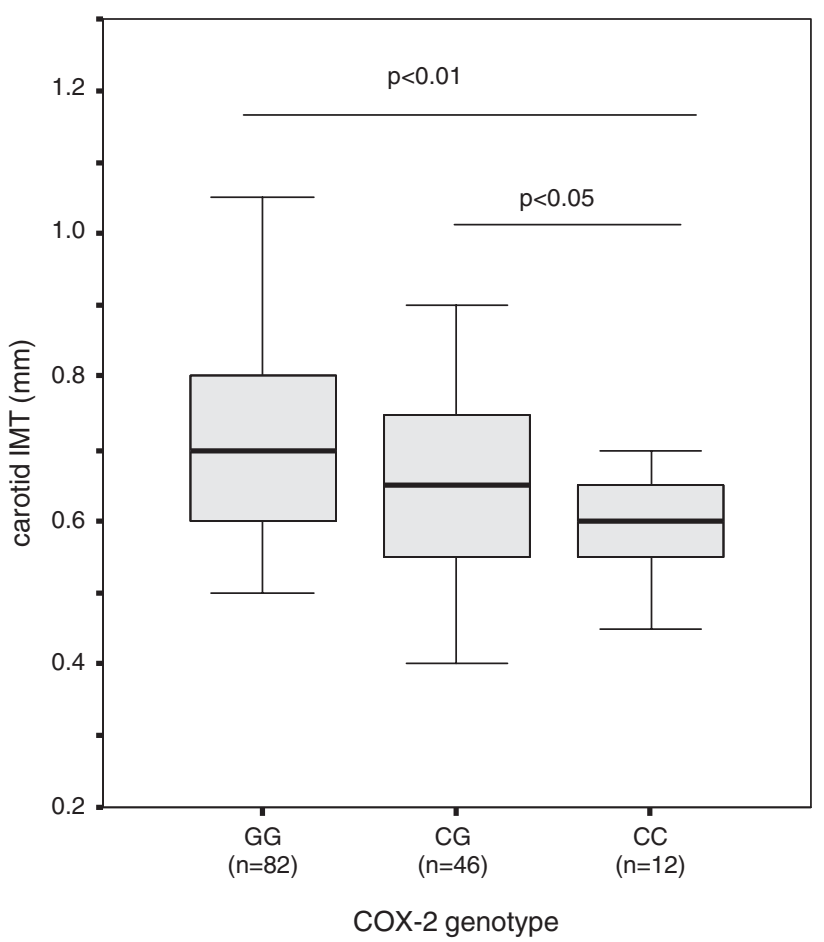

Fig. 1. Box-plot showing the carotid IMT in relation to the $-765 \mathrm{G}>\mathrm{C}$ COX-2 polymorphism. Median and percentile 75 th is reported. 
Table 4

Multiple linear regression analysis for the association of COX-2 $-765 \mathrm{G}>\mathrm{C}$ polymorphism with carotid IMT in hypercholesterolemic subjects

\begin{tabular}{lllr}
\hline Genotypes & $R(95 \% \mathrm{CI})$ & $p$ & \multicolumn{2}{c}{$\mathrm{R}^{\mathrm{a}}(95 \% \mathrm{CI})$} \\
\hline GG & Referent & - & - \\
GC & $-0.18(-0.34$ to -0.02$)$ & ns & $-0.25(-0.40$ to -0.09$)$ \\
CC & $-0.22(-0.37$ to -0.06$)$ & 0.016 & $-0.29(-0.43$ to -0.13$)$ \\
\hline
\end{tabular}

${ }^{\text {a }}$ Adjusted for age, gender, smoking, hypertension, obesity and diabetes, IL-6, vWF, CRP and fibrinogen.

carotid IMT of $8.3 \%$ in homozygous CC compared to subjects with GG genotype.

\section{Discussion}

In a population sample of hypercholesterolemic subjects without clinically overt atherosclerotic disease, we show that the common variant $-765 \mathrm{G}>\mathrm{C}$ in the $\mathrm{COX}-2$ gene promoter can play a protective role on subclinical atherosclerosis and systemic inflammation. Subjects carrying the $\mathrm{C}$ allele had significantly lower COX-2 expression and reduced carotid IMT, as well as diminished levels of the inflammatory markers CRP, IL-6 and vWF, compared with GG homozygous subjects. Taken together, our results indicate that the $\mathrm{C}$ allele might offer some protection against clinical events related to atherosclerosis development.

A polymorphism in the $5^{\prime}$-flanking region of the gene $(-765 \mathrm{G}>\mathrm{C})$ has been associated with functional changes in COX-2 promoter activity in vitro [17]. Subjects with the C allele might be protected from systemic inflammation, since lower levels of CRP, an established marker of inflammation and cardiovascular risk, were observed in patients with clinical atherosclerosis. However, there is little information available regarding the possible influence of this polymorphism on COX-2 expression and atherosclerosis development in vivo as well as its possible association with reduced risk of cardiovascular events [17]. Recently, $\mathrm{C}$ allele has been shown to be associated with reduced risk of myocardial infarction, stroke [18] and a decreased risk of Alzheimer's disease [22]. Moreover, our group has shown that COX-2-dependent $\mathrm{PGE}_{2}$ release by blood monocytes is related to subclinical atherosclerosis in apparently healthy subjects exposed to cardiovascular risk factors $[11,12]$. COX-2 expression and $\mathrm{PGE}_{2}$ synthesis have been shown to promote the release and activation of MMPs likely involved in plaque growth and rupture $[10,23]$. These data prompted us to assess the functional relevance of that polymorphism in relation to inflammation and subclinical atherosclerosis, in a population of subjects free from clinically apparent cardiovascular disease.

We found, for the first time, that in hypercholesterolemic subjects the $\mathrm{C}$ allele was independently associated with reduced carotid IMT, an established surrogate of atherosclerosis [24], after adjusting for traditional cardiovascular risk factors. The model explained an $8.3 \%$ reduction in carotid IMT in CC homozygous compared with the remaining genotypes. These data would suggest that this polymorphism may offer some protection against clinical events related to atherosclerosis plaque development [25]. Since lower COX-2 expression could be demonstrated in this subgroup, an inflammation-related effect can be suggested on the mechanism or carotid arterial thickening [26]. In contrast, Cipollone et al. failed to demonstrate any effect of this SNP on lesion size in the coronary artery assessed by angiography in a population with clinical cardiovascular disease [18].

The fact that lower COX-2 expression was found in C allele carriers in the present study could partially account for a reduced COX-2-mediated inflammation-dependent plaque growth. Supporting these observations, we also found that the COX-2 polymorphism was associated with a reduction in systemic inflammation, $\mathrm{C}$ allele carriers showing significantly lower levels of CRP, IL-6 and vWF, an effect not due to statin treatment, since no differences in the proportion of patients using lipid-lowering agents were found. Whereas there are several evidences linking COX-2 expression and inflammation, the precise mechanism remains unclear [2729]. An association between COX-2 and IL- 6 has been established in macrophages via $\mathrm{PGE}_{2}$ [30]; furthermore, the magnitude of rise in CRP levels in cardiovascular patients was also found to be strongly dependent on the $-765 \mathrm{G}>\mathrm{C}$ polymorphism [17]; since IL-6 is known to regulate CRP [31,32], it can be speculated that this polymorphism influences CRP levels via IL-6, which is also supported by our present findings. Subjects homozygous for the C allele also showed lower vWF levels, suggesting reduced endothelial damage [33] as compared with the remaining genotypes. Whereas there are no reports of COX-2mediated induction of vWF, immunohistochemical studies have shown their colocalization in endothelial cells [34].

Taken together, we found hypercholesterolemic subjects carrying the $\mathrm{C}$ allele of the $-765 \mathrm{G}<\mathrm{C}$ COX-2 polymorphism exhibited a more favourable phenotypic response consisting of reduced carotid IMT and systemic inflammation. A main difference between genetic and pharmacological inhibition of COX-2 to protect against cardiovascular events [28], would be in the preserved endothelial function and reduced systemic inflammation by the SNP.

Some limitations of the present study must be recognized. Our population sample was relatively small with high male prevalence. In addition, the cross-sectional design does not allow us to draw conclusions regarding the value of COX-2 polymorphism in the prediction of cardiovascular events. In the multivariate analysis we tried to adjust for most of the possible confounders, but other genetic, 
metabolic and environmental factors not included in the present analysis could also influence the IMT. Finally, the effect of this polymorphism cannot be extrapolated to other populations at atherosclerotic risk.

In conclusion, we documented a functional effect of $-765 \mathrm{G}>\mathrm{C}$ polymorphism in the COX-2 promoter, causing lower COX-2 gene expression, associated with reduced inflammation and subclinical atherosclerosis in middle-aged asymptomatic hypercholesterolemic subjects. Further studies in larger populations are warranted in order to validate the clinical significance of this polymorphism for atherosclerotic protection in cardiovascular risk patients.

\section{Acknowledgements}

This work was supported by grants from the Pfizer Foundation (11/2002), the Department of Health, Gobierno de Navarra (2002), UTE project CIMA (University of Navarra) and RECAVA (Ministry of Health, Spain).

\section{References}

[1] Vane JR, Bakhle YS, Botting RM. Cyclooxygenases 1 and 2. Annu Rev Pharmacol Toxicol 1998;38:97-120.

[2] Turini ME, DuBois RN. Cyclooxygenase-2: a therapeutic target. Annu Rev Med 2002;53:35-57.

[3] Smith WL, Langenbach R. Why there are two cyclooxygenase isozymes. J Clin Invest 2001;107:1491-5.

[4] Tanabe T, Tohnai N. Cyclooxygenase isozymes and their gene structures and expression. Prostaglandins Other Lipid Mediat 2002; 68-69:95-114.

[5] Prescott SM, Fitzpatrick FA. Cyclooxygenase-2 and carcinogenesis. Biochim Biophys Acta 2000;1470:M69 - 78.

[6] Pisetsky DS, St. Clair EW. Progress in the treatment of rheumatoid arthritis. JAMA 2001;286:2787-90.

[7] Morita I. Distinct functions of COX-1 and COX-2. Prostaglandins Other Lipid Mediat 2002;68-69:165-75.

[8] Baker CS, Hall RJ, Evans TJ, et al. Cyclooxygenase-2 is widely expressed in atherosclerotic lesions affecting native and transplanted human coronary arteries and colocalizes with inducible nitric oxide synthase and nitrotyrosine particularly in macrophages. Arterioscler Thromb Vasc Biol 1999;19:646-55.

[9] Schonbeck U, Sukhova GK, Graber P, Coulter S, Libby P. Augmented expression of cyclooxygenase-2 in human atherosclerotic lesions. Am J Pathol 1999;155:1281-91.

[10] Cipollone F, Fazia M, Iezzi A, et al. Suppression of the functionally coupled cyclooxygenase-2/prostaglandin E synthase as a basis of simvastatin-dependent plaque stabilization in humans. Circulation 2003;107:1479-85.

[11] Paramo JA, Rodriguez JA, Beloqui O, Orbe J. Monocyte cyclooxygenase-2 activity: a new therapeutic target for atherosclerosis? Curr Drug Targets Cardiovasc Haematol Disord 2005;5:303-11.

[12] Beloqui O, Paramo JA, Orbe J, et al. Monocyte cyclooxygenase-2 overactivity: a new marker of subclinical atherosclerosis in asymptomatic subjects with cardiovascular risk factors? Eur Heart J 2005; $26: 153-8$.

[13] Adderley SR, Fitzgerald DJ. Oxidative damage of cardiomyocytes is limited by extracellular regulated kinases $1 / 2$-mediated induction of cyclooxygenase-2. J Biol Chem 1999;274:5038-46.

[14] Shinmura K, Tang XL, Wang Y, et al. Cyclooxygenase-2 mediates the cardioprotective effects of the late phase of ischemic preconditioning in conscious rabbits. Proc Natl Acad Sci U S A 2000;97:10197-202.
[15] Gilroy DW, Colville-Nash PR, Willis D, Chivers J, Paul-Clark MJ, Willoughby DA. Inducible cyclooxygenase may have anti-inflammatory properties. Nat Med 1999;5:698-701.

[16] Fritsche E, Baek SJ, King LM, Zeldin DC, Eling TE, Bell DA. Functional characterization of cyclooxygenase-2 polymorphisms. J Pharmacol Exp Ther 2001;299:468-76.

[17] Papafili A, Hill MR, Brull DJ, et al. Common promoter variant in cyclooxygenase-2 represses gene expression: evidence of role in acute-phase inflammatory response. Arterioscler Thromb Vasc Biol 2002;22:1631-6.

[18] Cipollone F, Toniato E, Martinotti S, et al. A polymorphism in the cyclooxygenase 2 gene as an inherited protective factor against myocardial infarction and stroke. JAMA 2004;291:2221-8.

[19] Paramo JA, Orbe J, Beloqui O, et al. Prothrombin fragment 1+2 is associated with carotid intima-media thickness in subjects free of clinical cardiovascular disease. Stroke 2004;35:1085-9.

[20] Smith LH, Boutaud O, Breyer M, Morrow JD, Oates JA, Vaughan DE. Cyclooxygenase-2-dependent prostacyclin formation is regulated by low density lipoprotein cholesterol in vitro. Arterioscler Thromb Vasc Biol 2002;22:983-8.

[21] Norata GD, Pirillo A, Pellegatta F, Inoue H, Catapano AL. Native LDL and oxidized LDL modulate cyclooxygenase- 2 expression in HUVECs through a p38-MAPK, NF-kappaB, CRE dependent pathway and affect PGE2 synthesis. Int J Mol Med 2004;14:353-9.

[22] Abdullah L, Ait-Ghezala G, Crawford F, et al. The cyclooxygenase 2 $-765 \mathrm{C}$ promoter allele is a protective factor for Alzheimer's disease. Neurosci Lett 2005 (Nov 2) (Electronic publication ahead of print).

[23] Cipollone F, Prontera C, Pini B, et al. Overexpression of functionally coupled cyclooxygenase-2 and prostaglandin E synthase in symptomatic atherosclerotic plaques as a basis of prostaglandin E(2)-dependent plaque instability. Circulation 2001;104:921-7.

[24] Mancini GB, Dahlof B, Diez J. Surrogate markers for cardiovascular disease: structural markers. Circulation 2004;109:IV22 - 30.

[25] Chambless LE, Heiss G, Folsom AR, et al. Association of coronary heart disease incidence with carotid arterial wall thickness and major risk factors: the Atherosclerosis Risk in Communities (ARIC) Study, 1987-1993. Am J Epidemiol 1997;146:483-94.

[26] Libby P, Ridker PM, Maseri A. Inflammation and atherosclerosis. Circulation 2002;105:1135-43.

[27] Linton MF, Fazio S. Cyclooxygenase-2 and inflammation in atherosclerosis. Curr Opin Pharmacol 2004;4:116-23.

[28] Bogaty P, Brophy JM, Noel M, et al. Impact of prolonged cyclooxygenase-2 inhibition on inflammatory markers and endothelial function in patients with ischemic heart disease and raised C-reactive protein: a randomized placebo-controlled study. Circulation 2004; 110:934-9

[29] Monakier D, Mates M, Klutstein MW, et al. Rofecoxib, a COX-2 inhibitor, lowers $\mathrm{C}$-reactive protein and interleukin-6 levels in patients with acute coronary syndromes. Chest 2004;125:1610-5.

[30] Williams JA, Shacter E. Regulation of macrophage cytokine production by prostaglandin E2. Distinct roles of cyclooxygenase-1 and -2. J Biol Chem 1997;272:25693-9.

[31] Humphries SE, Luong LA, Ogg MS, Hawe E, Miller GJ. The interleukin-6 - $174 \mathrm{G} / \mathrm{C}$ promoter polymorphism is associated with risk of coronary heart disease and systolic blood pressure in healthy men. Eur Heart J 2001;22:2243-52.

[32] Li SP, Goldman ND. Regulation of human C-reactive protein gene expression by two synergistic IL-6 responsive elements. Biochemistry 1996;35:9060-8.

[33] Paramo JA, Beloqui O, Colina I, Diez J, Orbe J. Independent association of von Willebrand factor with surrogate markers of atherosclerosis in middle-aged asymptomatic subjects. J Thromb Haemost 2005;3:662-4.

[34] Yamagata K, Matsumura K, Inoue $\mathrm{W}$, et al. Coexpression of microsomal-type prostaglandin E synthase with cyclooxygenase-2 in brain endothelial cells of rats during endotoxin-induced fever. J Neurosci 2001;21:2669-77. 